\title{
Teaching Video NeuroImages: Atypical Abnormal Eye Movements in PNPO-Related Epilepsy
}

Sara Pavitt, MD, Amanda G. Sandoval Karamian, MD, Gaurav Chattree, MD, Jenna Klotz, MD, and Shannon Beres, MD

Neurology ${ }^{\circledR}$ 2021;96:e1927. doi:10.1212/WNL.0000000000010861

A full-term female neonate developed focal motor seizures at 1 hour of life, followed by paroxysmal nonepileptic abnormal eye-head movements on day 5 (video 1). CSF revealed mild hypoglycorrhachia, borderline low CSF:serum glucose, and low pyridoxal-5'-phosphate (P5P). Genetic testing showed compound heterozygous mutations in the pyridoxamine $5^{\prime}$ phosphate oxidase (PNPO) gene consistent with P5P-dependent epilepsy. Aberrant gaze saccades with head jerks are classically described in GLUT-1 deficiency, ${ }^{1}$ though not described in other conditions with associated hypoglycorrhachia. PNPO-associated epilepsy has been associated with abnormal eye movements ${ }^{2}$ and should be considered when neonates present with seizures and aberrant saccades with coordinated head movements.

\section{Study Funding}

No targeted funding reported.

\section{Disclosure}

The authors report no disclosures relevant to the manuscript. Go to Neurology.org/ $\mathrm{N}$ for full disclosures.

\begin{tabular}{|c|c|c|}
\hline Name & Location & Contribution \\
\hline Sara Pavitt, MD & $\begin{array}{l}\text { Stanford Children's Health, } \\
\text { Palo Alto, CA }\end{array}$ & $\begin{array}{l}\text { Data collection, drafted the manuscript for } \\
\text { intellectual content }\end{array}$ \\
\hline $\begin{array}{l}\text { Amanda Sandoval } \\
\text { Karamian, MD }\end{array}$ & $\begin{array}{l}\text { Stanford Children's Health, } \\
\text { Palo Alto, CA }\end{array}$ & Drafted the manuscript for intellectual content \\
\hline Gaurav Chattree, MD & $\begin{array}{l}\text { Stanford Health Care, Palo Alto, } \\
\text { CA }\end{array}$ & $\begin{array}{l}\text { Data collection, revised the manuscript for } \\
\text { intellectual content }\end{array}$ \\
\hline Jenna Klotz, MD & $\begin{array}{l}\text { Stanford Children's Health, } \\
\text { Palo Alto, CA }\end{array}$ & $\begin{array}{l}\text { Data collection, revised the manuscript for } \\
\text { intellectual content }\end{array}$ \\
\hline Shannon Beres, MD & $\begin{array}{l}\text { Stanford Children's Health, } \\
\text { Palo Alto, CA }\end{array}$ & Revised the manuscript for intellectual content \\
\hline
\end{tabular}

\section{References}

1. Pearson TS, Pons R, Engelstad K, Kane SA, Goldberg ME, De Vivo DC. Paroxysmal eye-head movements in Glut1 deficiency syndrome. Neurology 2017;88:1666-1673.

2. Mills PB, Surtees RAH, Champion MP, et a. Neonatal epileptic encephalopathy caused by mutations in the PNPO gene encoding pyridox(am)ine 5'-phosphate oxidase. Hum Mol Genet 2005;14:1077-1086.
Correspondence

Dr. Pavitt

sara.pavitt2@ucsf.edu

\section{MORE ONLINE}

\section{Video}

$\rightarrow$ Teaching slides

http://links.lww.com/

WNL/B232 


\section{Neurology}

\section{Teaching Video NeuroImages: Atypical Abnormal Eye Movements in PNPO-Related Epilepsy}

Sara Pavitt, Amanda G. Sandoval Karamian, Gaurav Chattree, et al. Neurology 2021;96;e1927 Published Online before print September 10, 2020

DOI 10.1212/WNL.0000000000010861

This information is current as of September 10, 2020

\section{Updated Information \&} Services

References

Subspecialty Collections

Permissions \& Licensing

Reprints including high resolution figures, can be found at: http://n.neurology.org/content/96/14/e1927.full

This article cites 2 articles, 1 of which you can access for free at: http://n.neurology.org/content/96/14/e1927.full\#ref-list-1

This article, along with others on similar topics, appears in the following collection(s):

All Epilepsy/Seizures

http://n.neurology.org/cgi/collection/all_epilepsy_seizures Metabolic disease (inherited)

http://n.neurology.org/cgi/collection/metabolic_disease_inherited Neonatal

http://n.neurology.org/cgi/collection/neonatal

Neonatal seizures

http://n.neurology.org/cgi/collection/neonatal_seizures

Information about reproducing this article in parts (figures,tables) or in its entirety can be found online at:

http://www.neurology.org/about/about_the_journal\#permissions

Information about ordering reprints can be found online:

http://n.neurology.org/subscribers/advertise

Neurology ${ }^{\circledR}$ is the official journal of the American Academy of Neurology. Published continuously since 1951, it is now a weekly with 48 issues per year. Copyright () 2020 American Academy of Neurology. All rights reserved. Print ISSN: 0028-3878. Online ISSN: 1526-632X.

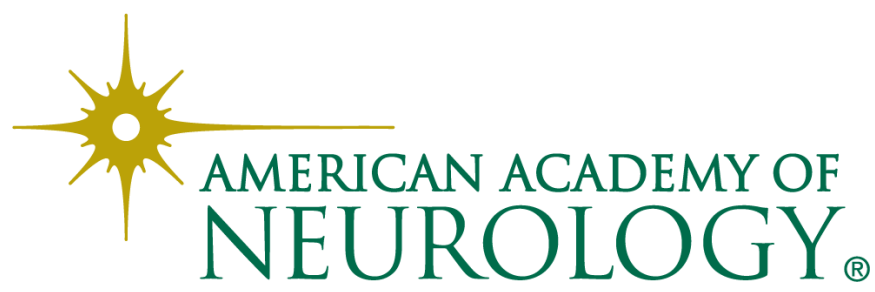

